\title{
Governança de recursos comuns: bacias hidrográficas transfronteiriças ${ }^{1}$
}

\author{
Governance of Common Pool Resources: transboundary basins
}

http://dx.doi.org/10.1590/0034-7329201400309

MATILDE DE SOUZA*
FRANCIELY TORRENTE VELOSO**
LETÍCIA BRITTO DOS SANTOS***
REBECA BERNARDO DA SILVA CAEIRO****

Rev. Bras. Polít. Int. 57 (2): 152-175 [2014]

Inovação institucional e governança de CP

A inovação institucional é aquela que redefine papéis e relacionamentos através de entidades independentes, para acelerar e ampliar a aprendizagem e reduzir riscos (Hagel 2007). Aplicado à gestão de águas, considera-se que o conceito de inovação institucional pode ser identificado na medida em que aperfeiçoamentos no desenho institucional permitirem: a redefinição de papéis dos diversos atores usuários da água; a redefinição do padrão de relacionamento entre eles; a incorporação do aprendizado sobre o bem em questão; a redução de riscos pela melhoria da qualidade e preservação da quantidade do bem e a prevenção de conflitos entre seus usuários.

O propósito desse artigo é discutir a inovação institucional para a governança de bacias hidrográficas transfronteiriças na América do Sul, tomando como aspecto central dos desafios à inovação o debate teórico acerca dos dilemas de cooperação relacionados ao compartilhamento de recursos naturais, notadamente os recursos hídricos. É importante ressaltar que o tema de que se ocupa este artigo, embora não muito explorado por estudiosos e pesquisadores do campo das Relaçóes

1 Este trabalho foi produzido a partir de pesquisa financiada pela FAPEMIG e pelo CNPq.

* Departamento de Relaçôes Internacionais, Pontifícia Universidade Católica de Minas Gerais, Belo Horizonte, Brasil (matilde@pucminas.br);

** Departamento de Relações Internacionais, Pontifícia Universidade Católica de Minas Gerais, Belo Horizonte, Brasil (franciely.torrente93@gmail.com);

*** Departamento de Relações Internacionais, Pontifícia Universidade Católica de Minas Gerais, Belo Horizonte, Brasil (letiicia@gmail.com);

**** Departamento de Relaçōes Internacionais, Pontifícia Universidade Católica de Minas Gerais, Belo Horizonte, Brasil (caeiro.rebeca@gmail.com). 
Internacionais no Brasil, tem sua relevância no fato de que cerca de 263 bacias hidrográficas são compartilhadas por dois ou mais países, o que corresponde a aproximadamente $60 \%$ de toda a água doce disponível no planeta (Earle, Jägerskog e Öjendal 2010). Dessas bacias, 38 encontram-se na América do Sul.

O fato do compartilhamento dos recursos hídricos por dois ou mais países, considerando a evidente interdependência entre os cousuários e os desafios políticos daí decorrentes, têm estimulado a constituição de tratados internacionais para o estabelecimento de formas compartilhadas de gerenciamento desses recursos. Observando apenas as duas maiores bacias hidrográficas da América do Sul, a bacia amazônica e a bacia do Prata, são 83 tratados bilaterais ou multilaterais entre os países ripárias (Oregon State University 2002). Além disso, um conjunto de diretrizes para a governança desse recurso tem sido estabelecido em fóruns internacionais, trajetória que se inicia nos anos 1960 e tem na Conferência de Dublin sua formulação mais completa (Souza e Tatemoto 2012). Considerando a dimensão local dos recursos hídricos e os estímulos por parte desses fóruns para a aplicação dessas diretrizes em estruturas institucionais produzidas para a governança das águas compartilhadas, avalia-se como de grande interesse para o campo das relações internacionais empreender pesquisas sobre processos de construção e/ou de inovação institucional para a governança desses recursos.

Para Ostrom (1999), discussões teóricas sobre governança de CPR² devem ter como foco central os problemas de ação coletiva cujas soluçôes descartem modelos que propugnam um poder estatal centralizado e pouco poroso. Tais modelos indicam a constituição de estruturas fortemente centralizadas, pouco efetivas e com altos custos de criação e manutenção. A grande heterogeneidade das condições objetivas dos CPRs seria impeditiva ao bom desempenho dessa estrutura institucional e problemas de ação coletiva não seriam solucionados, sendo, portanto, necessário produzir inovaçôes. Desse modo, e tomando-se os elementos considerados chave para a boa governança de recursos hídricos, a inovação deve ser pensada a partir de três dimensões: mudanças nas regras do jogo; descentralização e foco nos desafios locais.

Para Keohane e Ostrom (1995), tanto no nível doméstico quanto no internacional, indivíduos ou organizações envolvidos na governança de bens coletivos ou públicos podem fazer acordos de compromisso e são capazes de criar novas restrições institucionais que alterem a estrutura básica de seus incentivos. Desse modo, pode-se admitir que regras voltadas para a solução de problemas de compartilhamento de CPRs locais podem ser adequadas como solução de problemas de cooperação entre usuários de CPRs internacionais ou transfronteiriços.

Ostrom (1999) sugere desenhos específicos de estrutura de governança para tratar de problemas específicos. Certamente, a particularidade de um

2 CPR, Common Pool Resources, é um tipo de bem que se caracteriza pela baixa exclusão e alta rivalidade no uso. CPRs são bens de acesso aberto, difíceis de serem providos pelo mercado por falta de incentivos, embora não sejam bens públicos no sentido estrito do termo, por causa do problema da superlotação. Esses bens, contudo, estão sujeitos a sub-provisão por causa do acesso aberto. Em alguns CPRs como as águas de uma bacia, por exemplo, a exclusão de usuários a custos aceitáveis é praticamente impossível. 
desenho institucional não implica abandono de diretrizes gerais, mas envolve a discussão de como adequar tais diretrizes aos problemas locais. A autora propóe a institucionalização de estruturas mais autônomas dotadas de mecanismos de gestão e aposta em maior grau de independência, com liberdade dos atores ripários constituírem organizações locais para a governança do bem. O desafio seria como obter estratégias coordenadas, tendo em vista melhorar os benefícios de todos e reduzir danos coletivos. Esse desafio seria solucionado com a adoção de regras para orientação das condutas dos atores, tendo em vista a coordenação de interesses diversos. Para a autora, haverá maior aquiescência quanto ao cumprimento de tais regras se elas forem formuladas pelos próprios atores ripários do recurso.

Ostrom (1999) apresenta oito regras gerais que poderiam orientar a produção de instituições para a governança de um CPR: (1) fronteiras bem definidas - quem são os usuários e quais os limites do sistema de recurso; (2) congruência entre apropriação e regras de provisão e condições locais: regras de apropriação restringem o tempo, lugar, tecnologia e quantidade das unidades do recurso relacionadas às condições locais; as regras de provisão requerem trabalho, material ou recursos financeiros; (3) arranjos fundamentados em escolhas racionais coletivas: indivíduos afetados pelas regras operacionais podem participar de sua modificação; (4) monitoramento: os monitores - funcionários autorizados, que auditam o CPR e o comportamento dos usuários - devem ser "accountable" para os usuários e/ou são os próprios usuários; (5) gradação de sanções: usuários que violarem as regras sofrerão sanções graduais aplicadas pelos demais, pelos monitores ou por ambos; (6) mecanismos de resolução de conflitos: usuários e seus funcionários autorizados têm acesso rápido a arenas de baixo custo para resolver conflitos entre eles ou entre usuários e funcionários autorizados; (7) reconhecimento do direito mínimo de se organizar: direitos dos usuários de planejar suas próprias instituiçōes não devem ser ameaçados por autoridades governamentais externas; (8) ações aninhadas: apropriação, provisão, monitoramento, enforcement, resolução de conflitos e atividades de gestão são ações organizadas em múltiplas camadas de empreendimentos aninhados.

Considerando que essas regras constituem alterações no desenho da estrutura de governança, elas podem ser consideradas tecnologias organizacionais inovadoras, uma vez que tendem, por hipótese, a observar a redefinição de papéis e relacionamentos entre co-usuários. A partir desses elementos, pressupõe-se que o processo de mudança/inovação se faz a partir de um conjunto de regras institucionais, prescrições estabelecidas que impedem, exigem ou permitem alguma ação ou resultado. Esse processo significa, sempre, uma alteração no status quo, o que implica alteração nas estratégias de equilíbrio adotadas pelos atores em circunstâncias específicas.

Tsebelis (1998) trata o processo de mudança institucional como um processo endógeno, produzido pelas escolhas dos atores envolvidos e resultante da sua atividade política consciente. $\mathrm{O}$ autor afirma que a mudança institucional envolve um ou mais de um dos seguintes elementos: "(1) uma mudança no conjunto dos 
jogadores [...]; (2) uma mudança nas jogadas permitidas [...]; (3) uma mudança na sequência do jogo [...]; (4) uma mudança na avaliação disponível [...]" (Tsebelis 1998, 98). Esses elementos podem ser adicionados à perspectiva de Ostrom (1999) a respeito da mudança institucional, conforme mostra a Figura 1.

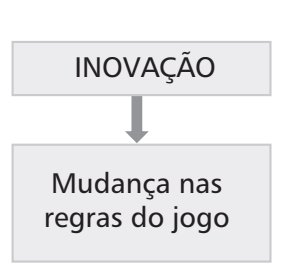

Figura 1. Inovação na gestão de CPR: contribuições de Ostrom (1999) e Tsebelis (1998).
I. (1) Fronteiras bem definidas / mudança no conjunto dos jogadores;

II. (2) Congruência entre apropriação e regras de provisão e condiçōes locais + (3) Arranjos fundamentados em escolhas racionais coletivas + (4) Monitoramento / mudança nas jogadas permitidas + mudança na sequência do jogo com (8) Açōes aninhadas;

III. (5) Gradação de sanções + (6) Mecanismos de resolução de conflitos + (7) Reconhecimento do direito mínimo de se organizar / mudança na avaliação disponível.

Fonte: Elaborado pela Equipe da Pesquisa.

Tsebelis (1998) classifica as instituições como eficientes - aquelas que melhoram as condiçóes de todos ou quase todos os indivíduos ou grupos; e redistributivas - aquelas que melhoram as condiçôes de um grupo em detrimento de outro. Como a mudança institucional é uma alteração nas condições de interação que depende de uma mudança na estratégia de equilíbrio num dado contexto, a mudança institucional sempre implicará algum grau de redistribuição. Essa redistribuição pode caminhar no sentido de maior simetria entre os atores, produzindo uma instituição eficiente ${ }^{3}$. Esta, em linhas gerais, se aproxima, em sua definição teórica, daquelas oito regras sugeridas por Ostrom (1999) e, em suas consequências práticas, aos princípios gerais orientadores do que seriam, na opinião de participantes de fóruns internacionais, regras adequadas para a produção das condições objetivas de governança dos recursos hídricos. Assim, pode-se admitir que a mudança institucional envolve inovação institucional. Contudo, pensar processos de mudança que incorporem aspectos de inovação demanda, ainda, considerar algumas variáveis que têm informado o estudo da governança de CPRs.

Isto posto, apresenta-se o problema central a ser investigado: considerando como pressuposto que os processos domésticos de inovação do desenho institucional para a governança de águas nos países objeto deste estudo se inspiram em princípios comuns, internacionalmente aceitos como adequados para essa finalidade, quais os efeitos dessa inovação face aos desafios da produção de instituições voltadas para a governança das águas transfronteiriças? A inovação institucional doméstica propicia a solução de dilemas de ação coletiva no âmbito interestatal, produzindo condições favoráveis para a solução de problemas relativos a governança de CPRs internacionais?

3 Para Tsebelis, na obra citada, instituições eficientes são aquelas que facilitam a comunicaçăo e o monitoramento; permitem contratos de compromisso; modificam a matriz de payoff; transformam o jogo no qual os atores estão envolvidos. 
São duas as hipóteses centrais: (1) quanto maior a convergência entre as normas institucionais adotadas localmente, maior a possibilidade de cooperação para a criação de instituições para governança de recursos hídricos compartilhados; (2) quanto maior o grau de inovação das normas domésticas, mais inovador será o desenho institucional proposto para a gestão compartilhada.

Para operacionalizar o teste das hipóteses, foi elaborado um modelo que conjugou três variáveis explicativas do processo de inovação institucional (Tabela 1). A estas variáveis foram atribuídas dimensōes e, para permitir a análise, estabeleceuse um conjunto de indicadores para cada uma das dimensões.

Tabela 1. Síntese geral do modelo analítico.

\begin{tabular}{|c|c|c|}
\hline Variável & Dimensōes & Indicadores \\
\hline \multirow[t]{14}{*}{$\begin{array}{l}\text { 1. Mudança nas } \\
\text { regas do jogo }\end{array}$} & \multirow{4}{*}{$\begin{array}{l}\text { 1.1. Boa delimitação } \\
\text { das fronteiras } \\
+ \text { mudança no } \\
\text { conjunto dos } \\
\text { jogadores }\end{array}$} & $\begin{array}{l}\text { - realização de reuniões ou seminários } \\
\text { bilaterais ou multilaterais para discussão do } \\
\text { compartilhamento }\end{array}$ \\
\hline & & $\begin{array}{l}\text { - criação de comissões ou grupos de trabalho } \\
\text { para estudo da questão }\end{array}$ \\
\hline & & $\begin{array}{l}\text { - existência de diretoria ou representantes eleitos } \\
\text { nessas comissões ou grupos de trabalho }\end{array}$ \\
\hline & & $\begin{array}{l}\text { - reuniōes desses grupos, sua periodicidade e os } \\
\text { principais temas tratados }\end{array}$ \\
\hline & \multirow{5}{*}{$\begin{array}{l}\text { 1.2. Congruência entre } \\
\text { apropriação e } \\
\text { regras de provisão } \\
\text { e condiçôes locais, } \\
\text { monitoramento, } \\
\text { mudança nas } \\
\text { jogadas permitidas, } \\
\text { mudança na } \\
\text { sequência do jogo } \\
\text { e ações aninhadas }\end{array}$} & - direito de outorga \\
\hline & & - saneamento \\
\hline & & $\begin{array}{l}\text { - integração entre as agendas azul (água), marrom } \\
\text { (esgotos e resíduos) e verde (florestas) }\end{array}$ \\
\hline & & - mecanismos para coleta de informações \\
\hline & & $\begin{array}{l}\text { - existência ou não de distribuição dos custos para } \\
\text { gerar e monitorar informaçôes sobre a bacia }\end{array}$ \\
\hline & \multirow{3}{*}{$\begin{array}{l}\text { 1.3. Sanções e resolução } \\
\text { de conflitos }\end{array}$} & - mecanismos \\
\hline & & - gradação \\
\hline & & - mudança na avaliação disponível \\
\hline & \multirow[t]{2}{*}{ 1.4. Participação } & - reconhecimento do direito de se organizar \\
\hline & & - arranjos fundamentados em escolhas coletivas \\
\hline \multirow{3}{*}{$\begin{array}{l}\text { 2. Descentralização } \\
\text { do Processo } \\
\text { Decisório }\end{array}$} & \multirow[t]{3}{*}{ 2.1. Descentralização } & - existência de comissão ou comitê local \\
\hline & & - capacidade de tomar decisão \\
\hline & & - formato da gestão \\
\hline \multirow[t]{4}{*}{$\begin{array}{l}\text { 3. Foco nos } \\
\text { desafios locais }\end{array}$} & \multirow{4}{*}{$\begin{array}{l}\text { 3.1. Participação dos } \\
\text { usuários na gestão } \\
\text { da bacia }\end{array}$} & $\begin{array}{l}\text { - como stakeholders são afetados por decisões } \\
\text { tomadas }\end{array}$ \\
\hline & & - posição dos stakeholders face às decisões tomadas \\
\hline & & - conflitos \\
\hline & & - mecanismos para resolução de conflitos \\
\hline
\end{tabular}

Fonte: Elaboração própria. 
Com base nesse modelo foi processado um conjunto de documentos com o auxílio do Software Atlas TI, o que permitiu verificar as correlaçōes entre indicadores, dimensões e variáveis.

As bases empíricas para o modelo foram obtidas através da análise exaustiva de um conjunto de documentos de fóruns internacionais ${ }^{4}$ nos quais o tema foi exaustivamente debatido. Da análise desse material foram identificados seis aspectos que são consenso em todos eles como adequados para a governança das águas: (1) maior grau de descentralização e mais ampla participação, com mais autonomia das unidades político-administrativas; (2) participação dos usuários e da sociedade organizada através de sua inserção na tomada de decisão, com capacidades para influir na elaboração de políticas locais por meio da metodologia bottom-up, mais adequada e eficiente à governança dos recursos hídricos. Como aponta Ostrom (1999), isso melhoraria a produção da informação, sua qualidade e difusão, além de ampliar a capacidade de monitoramento e prever formas de punição, com custo zero, ou perto disso, de administração; (3) adoção da gestão das águas por bacia hidrográfica, o que permite a clara delimitação das fronteiras da área de abrangência territorial de uma dada bacia, como apontado por Ostrom (1999), possibilitando o planejamento e a organização da gestão de águas no nível doméstico ou transfronteiriço; (4) maior integração dos organismos criados para executar as atividades de governança como, por exemplo, a incorporação de outras questôes como o uso dos solos e a preservação das florestas; (5) criação de regras claras que permitam observar o princípio do valor econômico da água, permitindo a geração de recursos financeiros para a própria bacia hidrográfica e inibindo o desperdício; (6) desenvolvimento de Sistema de Informação para o monitoramento de aspectos quanti-qualitativos dos recursos hídricos, melhorando as condições objetivas para a sua conservação e preservação.

Esses seis elementos são utilizados aqui como constituindo um tipo ideal, de modo a permitir uma forma de "mensuração" dos avanços feitos para se discutir o grau de inovação. Assim, considerando-se uma escala de 1 a 5 para mensurar o grau em que, pela leitura dos documentos disponíveis, a estrutura para a governança de águas dos países que compartilham as bacias hidrográficas em estudo se aproxima ou se distancia do tipo ideal proposto, sugere-se, por hipótese, que a inovação institucional é fruto da interação entre as dimensōes, conforme demonstra a Figura 2.

4 Todos os documentos que serviram de fonte de informações para a compilação da síntese apresentada no artigo estão devidamente citados nas referências bibliográficas. São eles: United Nations (1990), United Nations (1992), Unesco (2007), Unesco (2007a), Unesco (2007b), Unesco (2008; 2008a; 2008b; 2008c; 2008d), Unesco (2009; 2009a; 2009b; 2009c), Unesco (2010; 2010a; 2010b; 2010c), Unesco/Isarm (2010), Unesco (2011; $2011 \mathrm{a} ; 2011 \mathrm{~b} ; 2011 \mathrm{c})$. Esses documentos encontram-se devidamente citados nas Referências. 


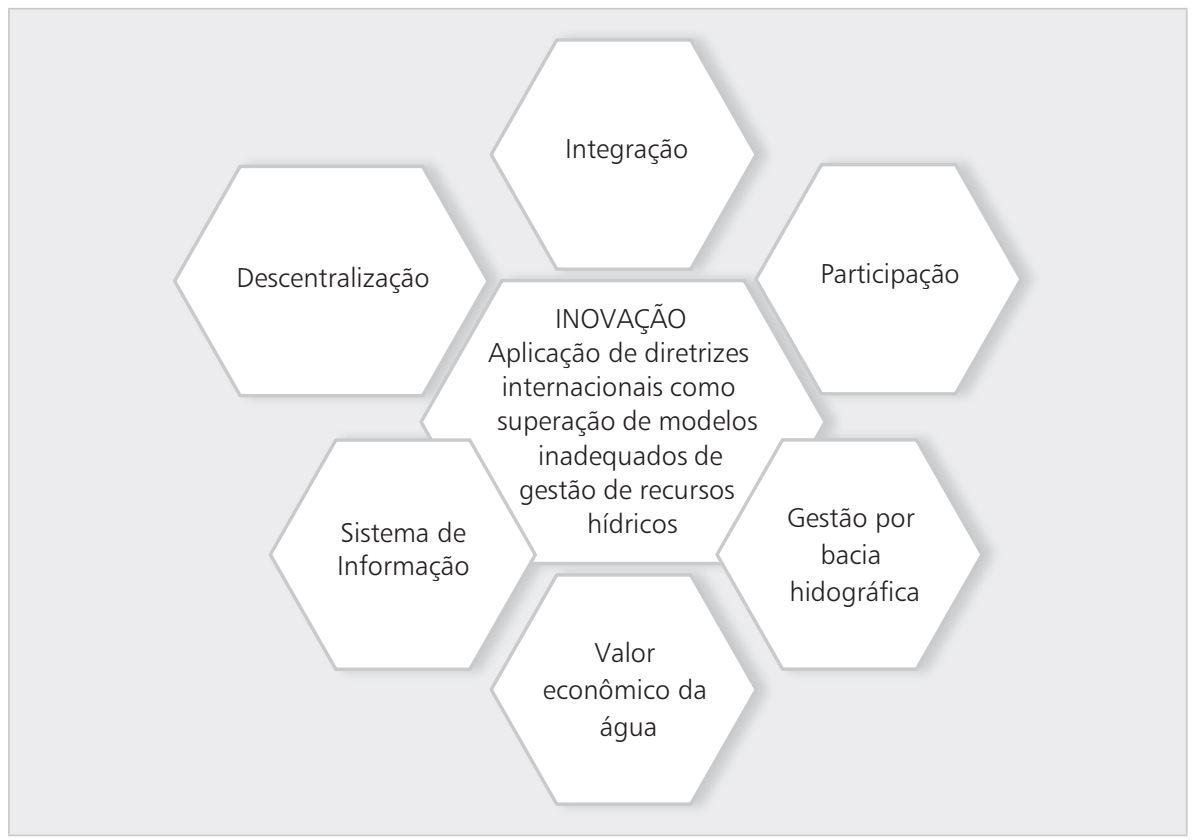

Figura 2. Inovação face às diretrizes internacionais de gestão de águas.

Fonte: Elaboração própria.

A seguir será feita uma breve explanação da política de recursos hídricos de Brasil, Bolívia, Paraguai, Peru e Uruguai. Os objetivos são: tomando as seis dimensões sistematizadas acima como orientaçóes gerais, identificar se os países em questão as adotam e, na medida do possível, em que grau; comparar as políticas dos países a partir dessas diretrizes para, posteriormente, discutir as iniciativas de gestão das bacias hidrográficas dos rios Apa, Acre e Quaraí e a bacia hidrográfica da Lagoa Mirim.

\section{Aspectos relevantes da estrutura institucional para a governança dos recursos hídricos: Brasil, Bolívia, Paraguai, Peru e Uruguai}

Foram identificadas diferenças importantes entre os desenhos institucionais da política de águas nos países em foco, embora se observe que, nos últimos cinco anos, esse desenho vem passando por alterações substantivas. $O$ foco nesses cinco países se deve ao fato de que eles vêm discutindo formas de gerenciamento integrado de recursos hídricos transfronteiriços. Já se verifica diálogo sistemático entre os organismos que gerenciam localmente esses recursos e são identificados avanços no que toca à gestão do uso da água enquanto um bem compartilhado, que se expressa no adensamento de tratados e acordos bilaterais ou trilaterais, considerando os casos aqui estudados. 
A estrutura brasileira para gestão de recursos hídricos ${ }^{5}$ é bastante descentralizada e prevê a participação dos diversos setores usuários, sendo composta por vários órgãos ligados entre si por uma relação hierárquica. Em linhas gerais, essa estrutura se organiza da seguinte forma: a Secretaria de Recursos Hídricos e Ambiente Urbano é um órgão subordinado ao Ministério do Meio Ambiente, que possui um Departamento de Recursos Hídricos; como órgão colegiado encontra-se o Conselho Nacional de Recursos Hídricos e como entidade vinculada, a Agência Nacional de Águas, autarquia prevista na estrutura de gestão e responsável pela implementação e coordenação pela governança compartilhada e integrada dos recursos hídricos, bem como pela regulação do acesso a água (ANA 2014). O Conselho Nacional de Recursos Hídricos, órgão deliberativo, se organiza em câmaras técnicas, dentre elas a Câmara Técnica de Gerenciamento de Recursos Hídricos Transfronteiriços (CTGRHT) cujas competências são propor diretrizes para a gestão de recursos hídricos compartilhados e promover o intercâmbio de conhecimento técnico e legal para que eventuais conflitos relacionados ao uso da água sejam solucionados de forma conjunta.

Apesar dessa estrutura complexa e atual, existem problemas de coordenação das açôes e atrasos na implantação da política em nível nacional. A gestão das águas é feita a partir de comitês de bacia cuja delimitação territorial observa a área de drenagem da bacia e não a demarcação política de estados e municípios. Esse fato, aliado à liberdade que os governos locais têm de escolher a forma de implementação do plano de recursos hídricos, fazem com que o nível de desenvolvimento da política nacional de recursos hídricos esteja em diferentes estágios, consideradas as diversas regiōes brasileiras.

$\mathrm{Na}$ Bolívia, a ausência de um órgão central coordenador dificulta o estabelecimento de parcerias para a governança de águas compartilhadas. A inclusão da população no processo de tomada de decisão e implementação da política de recursos hídricos, bem como a intensificação das discussões sobre o saneamento básico aconteceram a partir do ano de 1992, com a Lei do Meio Ambiente (Miranda 2009). A estrutura de gerenciamento, organizada a partir do Ministério do Meio Ambiente e Água, criado em 2006, prevê cinco órgãos dependentes e vinculados: o Conselho Técnico Social, responsável pelo diálogo do Ministério com a população; o Conselho Interinstitucional da Água, que cuida da relação do Ministério com as organizações sociais e econômicas; o Vice Ministério de Serviços Básicos, que trata do saneamento básico; o Vice Ministério da Irrigação; e o Vice Ministério de Bacias Hidrográficas e Recursos Hídricos, cuja principal função é a proteção, preservação e desenvolvimento sustentável tanto das águas nacionais quanto internacionais. (Miranda 2009).

No Paraguai verifica-se, subordinada à Secretaria do Meio Ambiente (Paraguai 2010), a Dirección General de Protección y Conservación de los Recursos Hídricos,

5 Lei Federal No 9433, de 08 de janeiro de 1997. 
cujas funções principais são "elaborar e propor políticas e estratégias de gestão dos recursos hídricos e suas bacias hidrográficas (...) e formar uma base para a

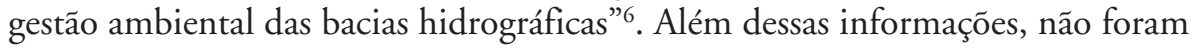
localizadas, no Website do governo paraguaio, outras normas domésticas acerca da gestão de águas.

O Peru dispõe de um sistema nacional de gestão de recursos hídricos integrado pela Autoridade Nacional da Água, ANA, e diversos ministérios relacionados. $\mathrm{O}$ processo de modernização do modelo de gestão aconteceu a partir das diretrizes do Decreto Lei No 17.752 de 2009, que substitui o decreto de 1969 e cria o Sistema Nacional de Gestão dos Recursos Hídricos (SNGRH). O SNGRH, a partir de instrumentos como a Política Nacional Ambiental, a Política e Estratégia Nacional de Recursos Hídricos, o Plano Nacional de Recursos Hídricos e os Planos de Gestão de Recursos Hídricos nas bacias hidrográficas, desenvolve ações como: avaliação da água e da gestão integrada, prioridade de acesso a água, participação da população, garantia de segurança jurídica, respeito ao uso da água pelas comunidades camponesas e nativas, a descentralização e a gestão integrada e participativa por bacias hidrográficas e tutela jurídica; além da articulação entre os níveis federal, regional e local. (Peru 2012).

No Uruguai, o código de Águas estabelecido pela Lei 14.859, de 1978, estabelece que o Estado deve promover o estudo, a conservação e o aproveitamento integral e simultâneo ou sucessivo das águas e a ação contra seus efeitos nocivos, competindo a ele: formular a política nacional de águas e concretizá-la em programas correlacionados ou integrados com a programação geral do país e com os programas para regiōes e setores; determinar o direito de outorga e a distribuição dos recursos por regiões e por tipos de uso da água. (Yelpo e Serrentino 2000). A gestão é setorial e bastante dispersa em diversos órgãos da administração pública. Foram criados dois órgãos com função consultiva e deliberativa, a Comissão Técnica Assessora de Proteção do Meio Ambiente (COTAMA) e o Grupo de Trabalho, com o objetivo de assessoramento e de coordenação das entidades relacionadas a recursos hídricos. Além disso, existem as Juntas Assessoras para Irrigação, que agrupam vários setores da administração pública, representação dos irrigantes e sociedades de fomento rural e tem poder deliberativo. Não existe sistema de informação hidrológica

Com base nessas informações, foi elaborada a Tabela 1 para identificar a presença ou ausência das diretrizes internacionais já explicitadas, o que possibilitará avaliar o grau de inovação institucional.

6 Tradução nossa. Trecho original: Elaborar y proponer políticas y estrategias de gestión de los recursos hídricos y sus cuencas hidrográficas (...), formar una base para la gestión ambiental de las cuencas hidrográficas. 
Tabela 1. Aplicação das diretrizes internacionais de gestão de recursos hídricos: comparando Brasil Bolívia, Peru e Paraguai.

\begin{tabular}{|c|c|c|c|c|c|}
\hline $\begin{array}{l}\text { Princípios } \\
\text { e Diretrizes } \\
\text { Internacionais } \\
\text { de gestão }\end{array}$ & $\begin{array}{c}\text { Política } \\
\text { Brasileira } \\
\text { de Recursos } \\
\text { Hídricos }\end{array}$ & $\begin{array}{c}\text { Política } \\
\text { Boliviana } \\
\text { de Recursos } \\
\text { Hídricos }\end{array}$ & $\begin{array}{c}\text { Política } \\
\text { Paraguaia } \\
\text { de Recursos } \\
\text { Hídricos }\end{array}$ & $\begin{array}{l}\text { Política } \\
\text { Peruana de } \\
\text { Recursos } \\
\text { Hídricos }\end{array}$ & $\begin{array}{c}\text { Política } \\
\text { Uruguaia } \\
\text { de Recursos } \\
\text { Hídricos }\end{array}$ \\
\hline $\begin{array}{l}\text { Integração } \\
\text { à política } \\
\text { ambiental }\end{array}$ & $\begin{array}{l}\text { Tendência } \\
\text { positiva }\end{array}$ & $\begin{array}{l}\text { Tendência } \\
\text { positiva }\end{array}$ & $\begin{array}{l}\text { Setorialização, } \\
\text { com } \\
\text { superposição } \\
\text { de funçōes em } \\
\text { alguns órgãos }\end{array}$ & Sim & $\begin{array}{c}\text { Setorialização } \\
\text { e dispersão } \\
\text { nos órgãos } \\
\text { públicos }\end{array}$ \\
\hline $\begin{array}{l}\text { Participação } \\
\text { dos setores } \\
\text { interessados }\end{array}$ & Sim & Sim & Não faz alusão & Sim & Sim \\
\hline Descentralização & Sim & Sim & $\begin{array}{l}\text { Verificou-se } \\
\text { tendência } \\
\text { positiva, não } \\
\text { existe órgão } \\
\text { coordenador } \\
\text { da gestão; }\end{array}$ & Sim & Sim \\
\hline $\begin{array}{l}\text { Sistema de } \\
\text { Informação }\end{array}$ & Sim & Sim & Não faz alusão & Sim & Não \\
\hline $\begin{array}{c}\text { Bacia } \\
\text { Hidrográfica } \\
\text { como base } \\
\text { territorial }\end{array}$ & Sim & $\begin{array}{l}\text { Não, gestão } \\
\text { a partir de } \\
\text { três regiōes } \\
\text { integradas }\end{array}$ & $\begin{array}{c}\text { Tendência } \\
\text { positiva - } \\
\text { existe proposta } \\
\text { para definição } \\
\text { das bacias } \\
\text { como base }\end{array}$ & Sim & Sim \\
\hline Valor econômico & Sim & Sim & Sim & Sim & Sim \\
\hline
\end{tabular}

Fonte: Elaboração própria.

Para mensurar o grau de aproximação das políticas dos 5 países, atribuiu-se uma pontuação de 0 a 5 para cada uma das dimensões consideradas, tomando como parâmetro as políticas dos países como informação de base e a síntese das diretrizes internacionais como a meta a ser alcançada. Tomou-se o 0 como a medida mais distante do modelo ideal e o 5 como a medida mais próxima desse modelo. Aplicado o modelo, tem-se a Tabela 2 e a Figura 3 a seguir. 
Tabela 2. Grau de Inovação Institucional.

\begin{tabular}{|l|c|c|c|c|c|}
\hline \multirow{2}{*}{ Dimensões } & \multicolumn{5}{c|}{ Grau de Inovação Institucional } \\
\hline & Brasil & Bolívia & Paraguai & Peru & Uruguai \\
\hline Integração & 3 & 1 & 1 & 3 & 1 \\
\hline Participação & 3 & 2 & 1 & 3 & 3 \\
\hline Descentralização & 4 & 3 & 1 & 4 & 3 \\
\hline Sistema de Informação & 5 & 1 & 1 & 3 & 1 \\
\hline Gestão por bacia hidrográfica & 5 & 3 & 2 & 4 & 3 \\
\hline Valor econômico da água & 3 & 1 & 1 & 3 & 3 \\
\hline
\end{tabular}

Fonte: Elaboração própria.

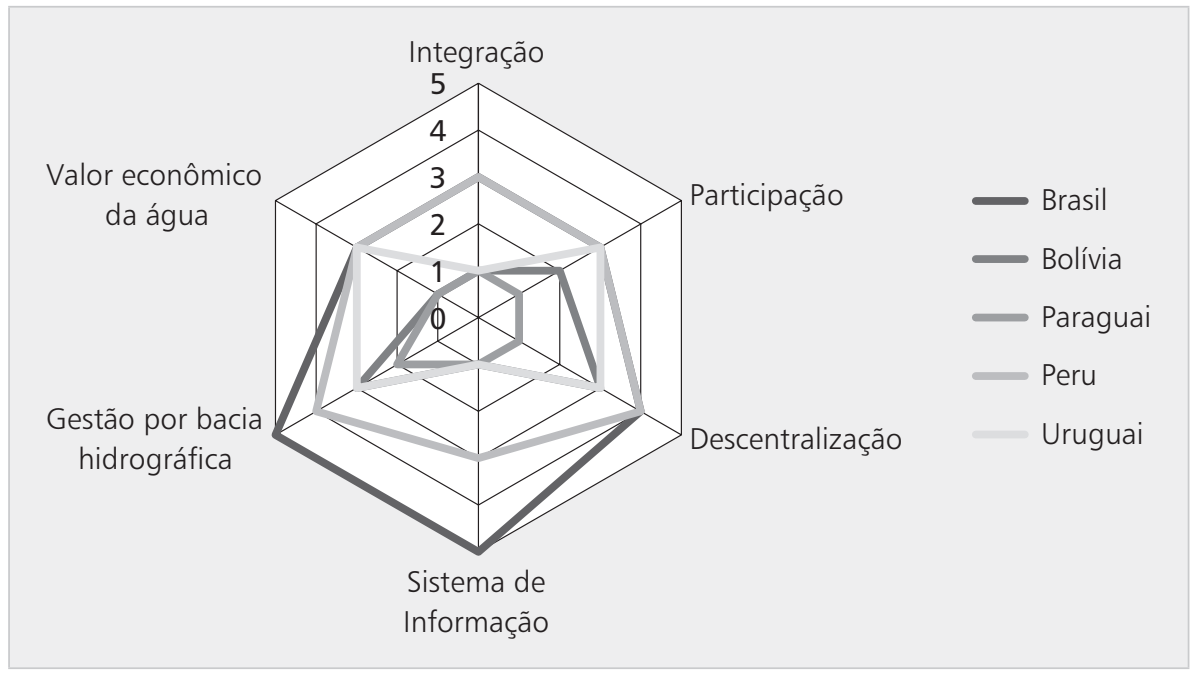

Figura 3. Grau de Inovação Institucional.

Fonte: Elaboração própria.

A partir das diferenças apresentadas, e sendo que o Brasil é o país que apresenta estrutura mais próxima ao tipo ideal, a questão relevante é compreender os padrões de interação estabelecidos entre o Brasil e os demais países para a gestão das águas transfronteiriças, com o propósito de discutir como essas estruturas podem afetar as iniciativas para a governança compartilhada dos recursos hídricos transfronteiriços e se são bem sucedidas nesse aspecto. 


\section{Estudos de caso}

Os estudos de caso que se seguem têm o objetivo de demonstrar de que modo as estruturas institucionais descritas, bem como as diferenças existentes entre elas no que concerne às seis diretrizes identificadas nas convenções internacionais, indicadoras de inovação institucional, interferem na gestão dos rios Apa, Acre, Quaraí e Lagoa Mirim.

\section{A Bacia do Rio Acre}

A bacia hidrográfica do Rio Acre localiza-se na Amazônia Sul-Ocidental, fronteira entre Brasil, Bolívia e Peru; sendo que cada um dos países possui uma porção de $41 \%, 33 \%$ e $26 \%$, respectivamente. O rio Acre banha dez cidades brasileiras, uma boliviana e uma peruana (Reis e Maldonado 2006). Atualmente, as principais atividades econômicas desenvolvidas na região da bacia do rio Acre são as extrativas, principalmente a pesca, além da criação de gado, agricultura de subsistência, caça e extração de recursos florestais. O aumento populacional e as mudanças no uso da terra têm provocado a intensificação do desmatamento e das queimadas, criando paisagens degradadas de difícil recuperação. O despejo de dejetos é um dos principais problemas do rio Acre (Acre 2008).

A inserção do debate sobre a bacia do rio Acre na CTGRHT se deu a partir da 33a reunião dessa Câmara, em 2006, por meio de um convite feito aos integrantes para que participassem da Oficina sobre aspectos legais e açôes estratégicas para a gestão compartilhada da bacia trinacional do rio Acre: Brasil, Bolivia e Peru, organizada pelos membros da iniciativa de integração denominada MAP (Madre de Díos - PE, Acre - BR e Pando - BO) (CTGRHT/CNRH 2006). A partir da discussão promovida nessa oficina por ocasião da $35^{\mathrm{a}}$ reunião da CTGRHT, foi proposta a criação de um Grupo de Trabalho, GT. Esse GT, existente entre os anos 2006-2010, teria a responsabilidade de, conforme diretrizes e dinâmica da CTGRHT, elaborar uma proposta de acordo para a gestão integrada da bacia, bem como uma proposta de Moção (Moção no 59, de 20 de setembro de 2011), ao Conselho Nacional de Recursos Hídricos (CNRH) brasileiro, para instigar órgãos domésticos relacionados à fiscalização ambiental a terem mais atenção às necessidades da bacia (CTGRHT/CNRH 2006a).

$\mathrm{Na} 54^{\mathrm{a}}$ reunião dessa Câmara, uma proposta para o acordo trinacional foi encaminhada aos ministérios competentes. Para viabilizar o Acordo, foi constituída a Comissão Trinacional Brasil-Bolívia-Peru para o Desenvolvimento Sustentável e a Gestão Integrada da Bacia Hidrográfica do Rio Acre, composta por membros do Ministério das Relaçôes Exteriores de cada parte, bem como por representantes de órgãos responsáveis pela gestão de recursos hídricos em cada país. A sede permanente ficaria no Ministério de Relaçóes Exteriores de uma das partes, com alternância anual e sedes operativas nas cidades de Pando (Bolívia), 
Acre (Brasil) e Madre de Díos (Peru). São funções da referida comissão: promover o desenvolvimento econômico sustentável da região; fiscalizar a situação ambiental da bacia; estudar e coordenar os assuntos técnicos, científicos, econômicos e sociais relacionados ao desenvolvimento da Bacia; implantar projetos elaborados para a região em parceria com os governos e fiscalizar o processo de sua execução. (CTGRHT/CNRH 2011a; CTGRHT/CNRH 2011b).

\section{A Bacia do Rio Apa}

A bacia hidrográfica do Rio Apa localiza-se na região de drenagem da grande Bacia do Prata, no extremo sul da Bacia do Alto Paraguai; sendo composta por seis municípios brasileiros e quatro paraguaios. As principais atividades econômicas na região da bacia são a criação de bovinos e a agricultura extensiva, além da mineração, extração de argila e extração de produtos da floresta. A vegetação da região tem sido afetada pela conversão da cobertura vegetal em pastagens para a criação de bovinos, uma das suas principais atividades econômicas. Outras atividades econômicas desenvolvidas são a extração de calcário, mármore, pedra e areia e indústrias produtoras de laticínios. Essas atividades têm aumentado a degradação ambiental, seja pela perda de solo pela erosão ou sedimentação ou pela aplicação de pesticidas (CTGRHT/CNRH 2003c).

A construção da gestão coordenada do rio Apa se iniciou antes mesmo da criação da CTGRHT, mas foi com essa Câmara e por meio do Grupo de Trabalho e do Acordo para a gestão do rio Apa, assinado entre Brasil e Paraguai, que ela ganhou força. Em 1998 foi criado, pela articulação dos municípios de ambos os lados da fronteira, o Consórcio Intermunicipal para o Desenvolvimento Integrado das Bacias dos Rios Miranda e Apa (CIDEMA). Em parceria com a AlterVida Centro de Estudios y Formación para El Ecodesarrollo, o CIDEMA promoveu dois encontros, um no Brasil e outro no Paraguai, com o objetivo de promoção da gestão coordenada da bacia. A discussão das necessidades dessa bacia entrou no âmbito da CTGRHT a partir de 2001, mais precisamente registrada na Ata da $\sigma^{a}$ reunião (19/12/2001), quando um dos representantes do CIDEMA foi convidado a expor os problemas dessa bacia, caracterizados principalmente pelo desmatamento, uso indevido do solo, poluição e conflito entre usuários dos dois países quanto à posse dos recursos, já que não existia nenhuma lei de outorga em nenhum dos lados (CTGRHT/CNRH 2001).

A partir dessa exposição, mais especificamente nas $7^{a}$ e $8^{a}$ reuniōes, foram feitas duas propostas para a solução dos problemas, semelhantes ao caso do rio Acre: a primeira dizia respeito à elaboração de uma moção ao $\mathrm{CNRH}$ que estabelecesse diretrizes internas e mobilizasse os órgãos brasileiros responsáveis pela fiscalização necessária na região acerca do monitoramento do uso dos recursos; e a segunda se referia ao encaminhamento de um acordo entre Paraguai e Brasil, que coordenasse, por meio da criação de uma comissão mista brasileiro-paraguaia 
para o desenvolvimento sustentável da bacia hidrográfica do rio Apa, as açóes das autoridades e da população afetadas pelo compartilhamento. (CTGRHT/CNRH 2002; CTGRHT/CNRH 2002a).

A $15^{\mathrm{a}}$ e $16^{\mathrm{a}}$ reuniōes da CT foram feitas em cidades da própria bacia, ocasião na qual vários grupos de usuários puderam expor suas experiências e dificuldades. Como resultado dessas reuniôes, foi criado na $20^{\mathrm{a}}$ ata da câmara o Grupo de Trabalho do Apa, composto por dezessete membros, dentre os quais se encontravam representados órgãos públicos estatais, organizaçôes sociais e grupos locais. Ao final do período estipulado para o GT, os documentos que causaram sua criação haviam sido produzidos, tanto a moção do CNRH (Moção no 14 , de 11 de dezembro de 2002) quanto o acordo de gestão compartilhada entre os países e a comissão mista responsável, em linhas gerais, por garantir sua observação, sendo válido observar a semelhança entre as soluções criadas para os problemas dessa bacia e do rio Acre. (CTGRHT/CNRH 2003; CTGRHT/CNRH 2003a; CTGRHT/CNRH 2002b; CTGRHT/CNRH 2006b).

\section{As Bacias da Lagoa Mirim e do rio Quaraí}

Optou-se por estudar simultaneamente as duas bacias pelo fato de que geralmente os tratados e discussōes existentes a respeito de uma se estendem a outra, já que são compartilhadas pelos mesmos países e se assemelham em critérios como atividades econômicas desenvolvidas e problemas ambientais da região. Ambas são compartilhadas por Brasil e Uruguai. O rio Quaraí banha quatro cidades brasileiras e três uruguaias, enquanto que a Lagoa Mirim já abrange dezenove municípios brasileiros e quinze uruguaios. Em ambos os casos, a principal atividade econômica é a agropecuária, sendo o cultivo de arroz a que envolve mais recursos e pessoas. De acordo com a Empresa Brasileira de Pesquisa Agropecuária (2010) e a Fundação Estadual de Proteção Ambiental Henrique Luiz Roessler (201?), outros gêneros cultivados são o feijão, milho, soja, laranja, pêssego e uva; e uma segunda atividade bem comum, embora mais restrita ao consumo local, é a pesca artesanal.

Conforme assinalado pela Divisão de Assessoramento Técnico do Ministério Público do Rio Grande do Sul, a poluição da bacia do rio Quaraí se deve aos seguintes fatores: esgotos domésticos e industriais lançados principalmente pelos municípios de Quarai e Barra do Quarai, depósito de resíduos e contaminação por agrotóxicos provenientes das lavouras. Além disso, existem áreas de mineração e de extração de argila, arenito, brita e saibro; extração de cascalho e areia nas margens e leito do curso d'água; e construção de açudes e canais de irrigação para as plantações, o que altera o ambiente que circunda a bacia. Na bacia da Lagoa Mirim, além do despejo dos resíduos domésticos, há também o de grandes volumes de resíduos gerados pelo processamento industrial do arroz (Empresa Brasileira de Pesquisa Agropecuária 2010). 
A construção de instituições responsáveis pelas bacias se deu antes mesmo da criação da Câmara Técnica, através do estabelecimento de tratados e criação de comissóes mistas responsáveis por sua execução. Datado de 11 de março de 1991, foi criado o Acordo de Cooperação para o Aproveitamento dos Recursos Naturais e o Desenvolvimento da Bacia do Rio Quaraí, para promover o desenvolvimento econômico e social da região, assim como a utilização racional da água e dos recursos naturais, animais e minerais, a recuperação e conservação do meio ambiente, manejo, conservação, utilização adequada dos recursos hídricos e recuperação dos solos. (Brasil 1991). A execução do Acordo se inspirou no Estatuto da Comissão Mista Brasileiro-Uruguaia para o Desenvolvimento da Bacia da Lagoa Mirim e é de responsabilidade da Comissão Mista Brasileiro-Uruguaia para o Desenvolvimento da Bacia do Rio Quaraí (CRQ) (Brasil 1977a).

O Tratado de Cooperação para o Aproveitamento dos Recursos Naturais e o Desenvolvimento da Bacia da Lagoa Mirim (Tratado da Bacia da Lagoa Mirim), de 07/07/1977, visa possibilitar o empreendimento de açōes conjuntas para a realização de obras de infraestrutura, realização de projetos conjuntos de desenvolvimento econômico e social da região para a melhoria das condiçóes locais e de vida da população. Esse Tratado objetivou garantir o abastecimento de água para uso doméstico, industrial e urbano, melhoria social e econômica dos habitantes da bacia, regularização das vazões e controle das inundações, defesa e utilização adequada dos recursos minerais, vegetais e animais e o incremento de meios de transporte e comunicação, em especial, da navegação. (Brasil 1977). A responsabilidade de execução do Tratado é da Comissão Mista BrasileiroUruguaia para o Desenvolvimento da Bacia da Lagoa Mirim (CLM), criada e estruturada pelas Notas de 26 de abril de 1963, 5 de agosto de 1965 e 20 de maio de 1974 (Brasil 1977a).

Segundo entrevista realizada pela equipe de pesquisa do presente trabalho, em 2011, com Manuel Maia (Diretor da Agência da Lagoa Mirim e Secretário Executivo da Sessão Brasileira da Comissão da Lagoa Mirim), a Agência da Lagoa Mirim (ALM) foi criada 1994, pelo Reitor da Universidade de Pelotas, Antônio Cezar Gonçalves Borges, para trabalhar e assumir as questôes relacionadas ao Tratado, operando como sua secretaria executiva na sessão brasileira (Maia 2011). A agência assumiu o compromisso de dar seguimento a todas as obrigaçóes e objetivos do Tratado e se responsabilizou pelo acervo do projeto - documentos e outros materiais relativos ao Tratado. (Maia 2011)

O caso do rio Quaraí começou a ser discutido pela CTGRHT em sua primeira reunião, em 04 de julho de 2000, com a observação de alguns dos problemas ambientais da bacia (CTGRHT/CNRH 2000). Na 7a reunião da Câmara, em 25/02/2002, começou a ser elaborada e discutida uma proposta de Moção ao $\mathrm{CNRH}$, aceita e transformada na Moção no9, que determinou, fundamentalmente, a construção de um dique para conter a poluição da água por resíduos $(\mathrm{CNRH}$ 2002c). Essa obra deveria ser prioridade do IBAMA e da ANA e que esses órgãos, 
juntamente com a Comissão Mista Brasileiro-Uruguaia para o Desenvolvimento da Bacia do Rio Quaraí - CRQ e a CORSAN, deveriam iniciar os procedimentos necessários para a realização da obra. (CTGRHT/CNRH 2002).

A Lagoa Mirim foi incorporada como tema de discussão na CTGRHT na 20a reunião, ocorrida no auditório da Agência da Lagoa Mirim entre os dias 17 a 19 de dezembro de 2003, oportunidade em que se apresentou uma proposta preliminar de construção de um Projeto Piloto de Gestão Integrada e Sustentável de Recursos Hídricos Transfronteiriços, baseado nas diretrizes e estruturas institucionais já determinadas pelo Tratado da referida bacia. A proposta concerne na criação de uma Sub-Comissão de Recursos Hídricos e Ambientais, composta por uma delegação de cada uma das partes, que seria responsável por congregar todos os órgãos nacionais envolvidos nesses referidos assuntos e coordenar a elaboração de políticas ambientais e de recursos hídricos em harmonia com a estrutura institucional correspondente no outro país (CTGRHT/CNRH 2003b).

Para que isso fosse concretizado, aventou-se a criação de um comitê de coordenação local para cada sub-bacia constituinte da bacia da Lagoa Mirim, comitê esse subordinado à sub-comissão e à Comissão. O Projeto foi encaminhado ao CNRH para, mediante aprovação, elaborar moção a ser encaminhada à Comissão Mista pelo CNRH para implementação do modelo de gestão proposto - Moção no 29, como foi chamada mais tarde. Para a Bacia do Rio Quaraí, a CTGRHT entendeu que deveria ser adotada a mesma estrutura organizacional e regimental da Seção Brasileira da Comissão da Lagoa Mirim, mantendo e homologando a atuação da Agência da Lagoa Mirim como organismo operacional de apoio técnico e administrativo também para a Bacia do Rio Quaraí (CNRH 2004).

\section{Conclusão}

A partir dessa breve descrição das discussões acerca da construção de estruturas institucionais para governança coordenada dos recursos hídricos entre os países ripários, é possível uma análise, à luz das variáveis e indicadores desenvolvidos no modelo analítico, das influências possíveis dos diferentes níveis de inovação institucional dos países sobre a gestão dos recursos hídricos, seja no sentido da liderança daqueles que têm um modelo de gestão mais desenvolvido, seja na dificuldade de estabelecer diretrizes ou, uma vez estabelecidas, implementá-las.

Em se tratando da primeira variável, a mudança das regras do jogo, quando se observa o primeiro aspecto que, de modo geral, define quem são os jogadores, a frequência das reunióes da câmara técnica, a diversidade dos atores que a compõem e o intercâmbio com outras áreas favorece a atividade propositiva de diretrizes, tanto em âmbito interno quanto internacional, já que nos casos aqui estudados e em outros coube à CTGRHT iniciar o processo de elaboração de regras que permitiram a constituição de mecanismos institucionais para a governança coordenada dos recursos hídricos compartilhados entre os países. A exceção, dentre 
os casos estudados, é o da Bacia Hidrográfica da Lagoa Mirim, cuja Comissão Mista foi criada no início da década de 1970 para viabilizar o desenvolvimento regional, sobretudo no que se refere à agricultura irrigada.

Quanto ao segundo e terceiro aspectos da primeira variável, que tratam do nível de institucionalização das regras referentes à apropriação e monitoramento das açóes, e dos mecanismos de resolução de conflitos, estes demonstram a tentativa de articulação das partes para a resolução dos problemas gerados exatamente pela ausência dessas regras. O conflito que se verificou na bacia do rio Apa pela apropriação ilegal da água por parte de produtores brasileiros, por exemplo, gerou a demanda pela discussão do direito de outorga por parte da ANA e da CTGRHT, que, em última instância, precisa conciliar de forma eficiente as normativas domésticas dos Estados com as propostas pelas diretrizes internacionais ou em acordos da própria região.

Com relação à exploração sustentável dos recursos, existe o intuito de integração da gestão ambiental pelo diálogo entre a promoção do saneamento básico, manutenção das florestas e matas ciliares e utilização da água para as diversas atividades, mas a dificuldade na aprovação dos acordos que, de fato, consagram esse processo demonstra as limitações ao desenvolvimento dessa visão.

No tocante aos mecanismos de monitoramento e resolução de conflito, a elaboração das moções do CNRH reafirmando o compromisso de uma série de órgãos domésticos brasileiros na fiscalização das ações nas bacias estudadas, se, por um lado, representam um instrumento pelo qual se dá a fiscalização das normas instituídas, por outro é limitada pelo exercício da soberania, fator que é reconhecido e também amenizado pelo estabelecimento de Tratados.

$\mathrm{O}$ acesso à informação talvez seja o fator que mais tem se observado na interação dos países para a gestão dos recursos, uma vez que a própria inclusão dos casos aqui estudados para análise da Câmara Técnica se deu por meio do diálogo com outras organizaçóes que, através de encontros, promoviam a troca de experiências entre os usuários dos recursos, independentemente das fronteiras.

A análise dos documentos consultados evidencia a preocupação das partes em incluir no processo decisório da gestão dos recursos os usuários das bacias, evidenciando a relevância das variáveis participação e descentralização para a compreensão do processo político envolvido na constituição dos mecanismos institucionais para a governança dos recursos hídricos transfronteiriços. Dois são os indícios centrais desse processo: a criação dos grupos de trabalho, que em linhas gerais foram responsáveis por orientar a produção de diretrizes para gestão a partir da consideração dos desafios e potencialidades locais, bem como das demandas dos usuários; e a realização das reuniōes da câmara técnica na região das bacias, onde era observado o direito de participação dos usuários por meio das organizações de produtores ou sociedade civil, além das iniciativas para maior envolvimento de organizações locais. 
Pode-se afirmar que a frequente liderança brasileira na construção de mecanismos de gestão nos quatro casos estudados se dá pelo fato de o Brasil possuir respostas institucionais desenvolvidas há mais tempo e, em diversos aspectos, mais consolidadas, o que pode ser mobilizado para a governança dos recursos hídricos. O Brasil possui recursos financeiros e técnicos que lhe facultam iniciar um movimento positivo para a cooperação. Além disso, em função das atividades econômicas realizadas nessas bacias, bem como pelo fato de serem regiōes de fronteira, além da relevância da preservação dos recursos de água potável, parece interessar ao Brasil promover condições para que a cooperação se estabeleça e que mecanismos institucionais sejam constituídos para a governança dos recursos hídricos e arrefecimento de possíveis conflitos nessas regiões.

Desse modo, e buscando compreender as circunstâncias que explicariam a cooperação para a governança de águas, com foco no estudo dos quatro casos abordados neste trabalho, pode-se admitir que: 1) o aspecto transfronteiriço da área de drenagem e a contiguidade territorial das bacias em questão; 2 ) as relações de cooperação interestatais historicamente constituídas na issue area estudada; 3) a estrutura de gestão dos recursos hídricos brasileira, que favoreceu ambiente político propício ao debate e formulação de propostas para a construção de acordos específicos para a gestão integrada das bacias em estudo; 4) a representação de grupos de interesse locais nessa estrutura, em diálogo com organismos sociais e estatais dos países ripários, todos esses elementos formam as condiçôes objetivas para os avanços verificados quanto à governança coordenada.

As experiências observadas de governança de águas transfronteiriças têm apontado para a coordenação das ações, pautada pelo marco regulatório doméstico dos países ripários. A pesquisa demonstra que a gestão compartilhada não é adotada e que os países alcançam estabelecer formatos institucionais que, principalmente, não ferem a sua soberania sobre os recursos hídricos. Estruturas para a governança coordenada foi o formato encontrado nos quatro casos estudados, e estas se objetivam pela criação de comissōes mistas com seçōes domésticas, com normativas comuns para a atuação na bacia, mas calcadas nas normas legais que regem a gestão das águas no território do respectivo país e que, a partir de demandas específicas para o uso compartilhado do recurso ou a sua exploração para finalidades específicas, o princípio da soberania estatal sobre o território tem prevalecido.

Quanto às estratégias adotadas pelos países para a construção dessas estruturas institucionais, pode-se dizer que estas se ancoram fortemente nas estruturas domésticas, cujo marco legal pauta as alternativas disponíveis. Observando-se esse patamar normativo, os processos são dinâmicos e de longa duração, com discussões e sedimentação de áreas de consenso quanto aos termos da cooperação, a concordância quanto ao resguardo da soberania dos Estados envolvidos e o não questionamento ou ausência de tentativas de alteração da política doméstica desses Estados para o setor. Claramente, busca-se a produção de benefícios e não foram 
estudadas aqui as bases de sua distribuição. Certamente, este pode ser mais um passo a ser dado nos esforços de investigação do tema na América do Sul.

\section{Referências bibliográficas}

ACRE (2008). Ministério Público. Caracterização Socioambiental das Bacias Hidrográficas do Estado do Acre. Rio Branco. Publicado em Mp.ac.gov [http://www.mp.ac.gov.br/wp-content/ files/Imagem05.pdf]. Disponibilidade: 26/05/2012.

BRASIL (2014). Agência Nacional de Águas. Institucional (2014). Publicado em Ana.gov [http://www2.ana.gov.br/Paginas/default.aspx]. Disponibilidade: 05/05/2014.

BRASIL (1977). Ministério das Relações Exteriores. O Tratado de Cooperação para o Aproveitamento dos Recursos Naturais e o Desenvolvimento da Bacia da Lagoa Mirim. Sistema de Atos Internacionais, publicado em: [http://dai-mre.serpro.gov.br/atos-internacionais/ bilaterais/1977/b_47/]. Disponibilidade: 15/08/2013.

BRASIL (1977a). Ministério das Relações Exteriores. Estatuto da Comissão Mista Brasileiro Uruguaia para o desenvolvimento da Bacia da Lagoa Mirim (CLM). Sistema de Atos Internacionais, publicado em: [http://dai-mre.serpro.gov.br/atos-internacionais/bilaterais/1977/b_49/]. Disponibilidade: 15/08/2013.

BRASIL (1997). Lei no 9433, de 08 de janeiro de 1997. Institui a Política Nacional de Recursos Hídricos, cria o Sistema Nacional de Gerenciamento de Recursos Hídricos, regulamenta o inciso XIX do art. 21 da Constituição Federal, e altera o art. $1^{\circ}$ da Lei no 8.001, de 13 de março de 1990, que modificou a Lei no 7.990, de 28 de dezembro de 1989. Presidência da República, Casa Civil, Sub Chefia para Assuntos Jurídicos. Brasília, 08 jan. de 1997. Publicado em Planalto. gov. [http://www.planalto.gov.br/ccivil_03/leis/19433.htm]. Disponibilidade: 15/11/2014.

BRASIL (1991). Ministério das Relações Exteriores. Acordo de Cooperação para o Aproveitamento dos Recursos Naturais e o Desenvolvimento da Bacia do Rio Quaraí. Sistema de Atos Internacionais, publicado em: [http://dai-mre.serpro.gov.br/atos-internacionais/bilaterais/19 91/b_6_2011-10-17-10-44-49/]. Disponibilidade: 15/08/2013.

BRASIL (2000). Ministério do Meio Ambiente, Conselho Nacional de recursos hídricos, Câmara Técnica de Gestão de Recursos Hídricos Transfronteiriços - CTGRHT. Ata da $1^{a}$ Reunião, realizada no dia 4 de Julho de 2000, publicada em: [http://www.cnrh.gov.br/ index.php?option=com_content $\&$ view $=$ article $\&$ id $=138$ :gtdiretrizes $\&$ catid $=30$ :grupos-detrabalho\&Itemid=84]. Disponibilidade: 02/08/2013.

BRASIL (2001). Ministério do Meio Ambiente, Conselho Nacional de Recursos Hídricos, Câmara Técnica de Gestão de Recursos Hídricos Transfronteiriços - CTGRHT. Ata da $\sigma^{a}$ Reunião, realizada no dia 19 de dezembro de 2001, publicada em: [http://www.cnrh.gov.br/ sitio.]. Disponibilidade: 02/02/2012.

BRASIL (2002). Ministério do Meio Ambiente, Conselho Nacional de Recursos Hídricos, Câmara Técnica de Gestão de Recursos Hídricos Transfronteiriços - CTGRHT. Ata da $7 a$ Reunião, realizada no dia 25 de fevereiro de 2002, publicada em: [http://www.cnrh.gov.br/ sitio.]. Disponibilidade: 02/02/2012.

BRASIL (2002a). Ministério do Meio Ambiente, Conselho Nacional de Recursos Hídricos, Câmara Técnica de Gestão de Recursos Hídricos Transfronteiriços - CTGRHT. Ata da $8^{a}$ Reunião, realizada em Brasília, maio de 2002, publicada em: [http://www.cnrh.gov.br/sitio.]. Disponibilidade: 02/02/2012. 
BRASIL (2002b). Ministério do Meio Ambiente Conselho Nacional de recursos hídricos. Moção número 14. 11 de dezembro de 2002, publicado em: [http://www.cnrh.gov.br/index. php?option=com_content\&view=article\&id=101]. Disponibilidade: 02/08/2013.

BRASIL (2002c). Ministério do Meio Ambiente, Conselho Nacional de recursos hídricos. Moção número 09. 14 de março de 2002, publicado em: [http://www.cnrh.gov.br/index. php?option=com_content\&view=article\&id=101.]. Disponibilidade: 02/08/2013.

BRASIL (2003). Ministério do Meio Ambiente, Conselho Nacional de recursos hídricos, Câmara Técnica de Gestão de Recursos Hídricos Transfronteiriços - CTGRHT. Perfil da Bacia do Rio Apa, publicada em: [www.cnrh.gov.br/index.php?option=com_content\&view=section \&id=13\&Itemid=84>] Disponibilidade: 10/05/2012.

BRASIL (2003a). Ministério do Meio Ambiente, Conselho Nacional de Recursos Hídricos, Câmara Técnica de Gestão de Recursos Hídricos Transfronteiriços - CTGRHT. Ata da 15a Reuniāo, realizada no dia 05 de maio de 2003, publicada em: [http://www.cnrh.gov.br/sitio.]. Disponibilidade: 02/02/2012.

BRASIL (2003b). Ministério do Meio Ambiente, Conselho Nacional de Recursos Hídricos, Câmara Técnica de Gestão de Recursos Hídricos Transfronteiriços - CTGRHT. Ata da 16a Reuniāo, realizada no dia 23 de junho de 2003, publicada em: [http://www.cnrh.gov.br/sitio.]. Disponibilidade: 02/02/2012.

BRASIL (2003c). Ministério do Meio Ambiente, Conselho Nacional de Recursos Hídricos, Câmara Técnica de Gestão de Recursos Hídricos Transfronteiriços - CTGRHT. Ata da 20a Reunião, realizada nos dias 17, 18 e 19 de dezembro de 2003, publicado em: [http://www.cnrh. gov.br/sitio.]. Disponibilidade: 02/02/2013.

BRASIL (2004). Ministério do Meio Ambiente, Conselho Nacional de recursos. Moção número 29. 29 de outubro de 2004, publicada em: [http://www.cnrh.gov.br/index.php?option=com content\&view=article\&id=101.] Disponibilidade: 02/08/2013.

BRASIL (2006). Ministério do Meio Ambiente, Conselho Nacional de Recursos Hídricos, Câmara Técnica de Gestão de Recursos Hídricos Transfronteiriços - CTGRHT (2006). Ata da 33a Reunião, realizada no dia 15 fevereiro de 2006. Publicado em CNRH.gov [http://www. cnrh.gov.br/sitio]. Disponibilidade 02/02/2012.

BRASIL (2006a) Ministério do Meio Ambiente, Conselho Nacional de Recursos Hídricos, Câmara Técnica de Gestão de Recursos Hídricos Transfronteiriços - CTGRHT (2006a). Ata da $35^{a}$ Reunião, realizada no dia 27 de setembro de 2006. Publicado em CNRH.gov [http://www.cnrh.gov.br/sitio. Acesso em 02 fev. 2012]. Disponibilidade 02/02/2012.

BRASIL (2006b). Ministério das Relaçōes Exteriores, Sistema de Atos Internacionais. Acordo de Cooperação entre a República Federativa do Brasile a República do Paraguai para o Desenvolvimento Sustentável e a Gestão Integrada da Bacia Hidrográfica do Rio Apa, publicado em: [http://daimre.serpro.gov.br/atos-internacionais/bilaterais/2006/b_136]. Disponibilidade: 15/08/2013.

BRASIL (2011). Ministério do Meio Ambiente, Conselho Nacional de recursos hídricos. Moção número 59, publicado em: [http://www.cnrh.gov.br/index.php?option=com content\&view=article\&id=101.]. Disponibilidade: 02/08/2013.

BRASIL (2011a), Ministério do Meio Ambiente, Conselho Nacional de Recursos Hídricos, Câmara Técnica de Gestão de Recursos Hídricos Transfronteiriços - CTGRHT. Ata da 54a Reunião, realizada no dia 09 de junho de 2011, publicado em CNRH.gov [http://www.cnrh. gov.br/sitio. Acesso em 02 fev. 2012]. Disponibilidade 02/02/2012. 
BRASIL (2011b), Ministério do Meio Ambiente, Conselho Nacional de recursos hídricos, Câmara Técnica de Gestão de Recursos Hídricos Transfronteiriços - CTGRHT. Acordo de Cooperação entre o Governo do Estado Plurinacional da Bolivia, o Governo da República Federativa do Brasil e o Governo da República do Peru para o Desenvolvimento Sustentável e a Gestão Integrada da Bacia Hidrográfica do rio Acre. Anexo da ata da 54a Reunião, realizada no dia 09 de junho de 2011, publicado em CNRH.gov [http://www.cnrh.gov.br/index.php?option=com_ docman\&task=cat_view\&gid=226\&Itemid=9]Disponibilidade em 15/08/2013.

EARLE, Anton; JÄGERSKOG, Anders; ÖJENDAL, Joakim. (2010). Transboundary water management: principles and practice. Earthscan. Stockholm International Water Institut in London and Washington DC. 2.

EMPRESA BRASILEIRA DE PESQUISA AGROPECUÁRIA (2010). Sustentabilidade Sócio Ambiental da Bacia da Lagoa Mirim, publicado em: [http://www.infoteca.cnptia.embrapa.br/ bitstream/doc/912638/1/Livrolagoamirimcomcapa.pdf]. Disponibilidade: 12/03/2013.

FUNDAÇÃO ESTADUAL DE PROTEÇÃO AMBIENTAL HENRIQUE LUIZ ROESSLER RS. (201?) U60: Quarai, publicado em: [http://www.fepam.rs.gov.br/qualidade/bacia_uru_ quarai.asp]. Disponibilidade: 12/03/2013.

HAGEL, John (2007). Institutional innovation, publicado em Edge perspectives [http://edgeperspectives.typepad.com/edge_perspectives/2007/10/institutional-i.html]. Disponibilidade: 23/03/2011.

KEOHANE, Robert O.; OSTROM, Elinor. Ed. (1995). Local commons and global interdependence: heterogeneity and cooperation in two domains, publicado em London: SAGE, 259 p.

MAIA, Manuel (2011). Entrevista sobre a gestão das bacias hidrográficas Lagoa Mirim e Quaraí. Sede da Agência de Desenvolvimento da Bacia da Lagoa Mirim. Rio Grande do Sul, Pelotas. 7/12/2011.

MIRANDA, G. A. P (2009). Estágio atual da gestão de recursos hidricos na Bolivia. Dissertação (Mestrado em Engenharia Ambiental) - Universidade do Estado do Rio de Janeiro, Programa de Pós-graduação em Engenharia Ambiental, Rio de Janeiro. Publicado em Peamb.eng.uerj [http://www.peamb.eng.uerj.br/trabalhosconclusao/2009/ GricelAlciraPortillodeMirandaPEAMB_2009.pdf]. Disponibilidade: 20/03/2012.

OREGON STATE UNIVERSITY (2002). Atlas of International Freschwater Agrements. [http:// www.transboundarywaters.orst.edu/publications/atlas/index.html] Consulta em 07/09/2014.

OSTROM, Elinor (1990). Governing the commons. The evolution of institutions for collective action. Cambridge: Cambridge University Press.

PARAGUAI. Secretaría Del Ambiente (2010). Funciones especificas. Publicado em Seam.gov. py [http://www.seam.gov.py/direccion-general-de-proteccion-y-conservacion-de-los-recursoshidricos/funciones-especificas.html]. Disponibilidade em 2/05/2010.

PERU. Ministerio de Agricultura, Autoridad Nacional Del Água (2012). Política y Estratégia Nacional de Recursos Hidricos. Publicado em Ana.gob.pe [http://www.ana.gob.pe/publicaciones/ publicaciones-2012/politica-y-estrategia-nacional-de-recursos-hidricos.aspx]. Disponibilidade: $15 / 08 / 2013$.

REIS, V. L.; MALDONADO, M. L. R. (2006). Bacia Trinacional do Alto Rio Acre. 2006. [http:// www.cnrh.gov.br/index.php?option=com_docman\&task=doc_download\&gid=692\&Itemid=] Disponibilidade: 10/05/2012. 
SOUZA, Matilde; TATEMOTO, Letícia C. B. (2012) Institutional Innovation in Water Management. In BILIBIO, C.; HENSEL, O. SELBACH, J. Sustainable water management in the tropics and subtropics - and case studies in Brazil. Vl. 4. Jaguarão/RS: Fundação Universidade Federal do Pampa. UNIKASSEL, PGCult-UFMA. [http://books.google.com.br/books/about/ Sustainable_water_management_in_the_trop.html?hl=pt-BR\&id=WktzAliHowMC].

TSEBELIS, George (1998). Jogos ocultos: escolha racional no campo da politica comparada. São Paulo: Edusp.

UNITED NATIONS (1990). Report of the Economic and Social Council. UNBISNET: New York. Publicado em United Nations.org [http://daccess-dds-ny.un.org/doc/UNDOC/GEN/ N90/166/98/PDF/N9016698.pdf?OpenElement]. Disponibilidade em: 21/03/2011.

UNITED NATIONS (1992). Report of the United Nations Conference on Environment and Development. General Assembly: New York. Publicado em United Nations. Org [http://www. un.org/documents/ga/conf151/aconf15126-1annex1.htm]. Acesso em: 21/03/2011.

UNESCO - UNITED NATIONS EDUCATIONAL SCIENTIFIC AND CULTURAL ORGANIZATION (2007). 4th Asian Regional Conference and 10th International Seminar on Participatory Irrigation Management (PIM). Water Events World Wide: Tehran. Publicado em Unesco.org, [http://www.unesco.org/water/water_events/Detailed/1468.shtml]. Disponibilidade em 24/03/2011.

UNESCO - UNITED NATIONS EDUCATIONAL SCIENTIFIC AND CULTURAL ORGANIZATION (2007a). 5th International Conference on Sewer Processes and Networks. Water Events World Wide: Delft. Publicado em Unesco. Org [http://www.unesco.org/water/ water_events/Detailed/1522.shtml]. Disponibilidade em 24/03/2011.

UNESCO - UNITED NATIONS EDUCATIONAL SCIENTIFIC AND CULTURAL ORGANIZATION (2007b). 9th International Scientific-Industrial Forum 'Ecological, Hydrometeorological and Energy Safety. Water Events World Wide: Nizhny Novgorod. Publicado em Unesco. Org. [http://www.unesco.org/water/water_events/Detailed/1453.shtml]. Disponibilidade em 24/03/2011.

UNESCO (2008). NGWA International Conference on Non-renewable Groundwater Resources. Water Events World Wide: Portland. Publicado em Unesco. Org [http://www.unesco.org/water/ water_events/Detailed/1570.shtml]. Disponibilidade em 24/03/2011.

UNESCO (2008a). Third International Conference on Managing Shared Aquifer Resources in Africa. Water Events World Wide: Tripoli. Publicado em Unesco. Org [http://www.unesco.org/ water/water_events/Detailed/1597.shtml]. Dosponibilidade em 24/03/2011.

UNESCO (2008b). 12th Biennial Conference of Euromediterranean Network: Hydrological Extremes in Small Basins. Water Events World Wide: Cracow. Publicado em Unesco. Org [http:// www.unesco.org/water/water_events/Detailed/1595.shtml]. Disponibilidade em 24/03/2011.

UNESCO (2008c). Water Down Under 2008. Water Events World Wide: Adelaide. Publicado em Unesco. Org. [http://www.unesco.org/water/water_events/Detailed/1485.shtml]. Disponibilidade 24/03/2011.

UNESCO (2008d). International Conference on Water Scarcity, Global Changes and Groundwater Management Responses. Water Events World Wide: Irvine. Publicado em Unesco. Org. [http://www.unesco.org/water/water_events/Detailed/1567.shtml]. Disponbilidade em 25/03/2011. 
UNESCO (2009). Third International Arab Healthy Water Conference. Water Events World Wide: Cairo. Publicado em Unesco.org [http://www.unesco.org/water/water_events/ Detailed/1858.shtml]. Disponibilidade em 25/03/2011.

UNESCO, UNITED NATIONS EDUCATIONAL SCIENTIFIC AND CULTURAL ORGANIZATION (2009a). International Conference on Urban Flood Management: Road Map Towards a Flood Resilient Urban Environment. Water Events World Wide: Paris,. Publicado em Unesco.org [http://www.unesco.org/water/water_events/Detailed/1850.shtml]. Disponibilidade 25/03/2011.

UNESCO (2009b). World Climate Conference-3 (WCC-3): Climate prediction and information for decision-making. Water Events World Wide: Geneva. Publicado em Unesco. Org. [http://www.unesco.org/water/water_events/Detailed/1840.shtml]. Disponibilidade em 25/03/2011.

UNESCO (2009c). Sixth International Scientific Conference on the Global Energy and Water Cycle (GEWEX) and the Second Integrated Land Ecosystem-Atmosphere Study (iLEAPS) Science Conference. Water Events World Wide: Melbourne. Publicado em Unesco. Org. [http://www. unesco.org/water/water_events/Detailed/1847.shtml]. Disponibilidade: 25/03/2011.

UNESCO (2010). Water History Conference Delft 2010. Water Events World Wide: Delft. Publicado em Unesco. Org. [http://www.unesco.org/water/water_events/Detailed/1996.shtml]. Disponibilidade: 25/03/2011.

UNESCO (2010a). International Conference on Arid and Semi Arid Development through Water Augmentation (ASADWA). Water Events World Wide: Valparaiso Publicado em Unesco. Org. [http://www.unesco.org/water/water_events/Detailed/2018.shtml]. Disponibilidade: 25/03/2011.

UNESCO (2010b). IWA-WHO Water Safety Conference: Managing Drinking Water Quality for Public Health. Water Events World Wide: Kuching. Publicado em Unesco. Org. Publicado em Unesco. Org. [http://www.unesco.org/water/water_events/Detailed/2067.shtml]. Disponibilidade: 25/03/2011.

UNESCO (2010c). Conference on Guarani Aquifer System "The Management of the Guarani Aquifer System: An Example of Cooperation. Water Events World Wide: São Paulo. Publicado em Unesco. Org. [http://maintenance.unesco.org/404/?host=www.unesco.org\&uri=/new/ en/natural-sciences/environment/water/wwap/index.shtml\#gas_abstracts]. Disponibilidade: 25/03/2011.

UNESCO (2011). The Future of Urban Water: Solutions for Livable and Resilient Cities. Water Events World Wide: Paris. Publicado em Unesco. Org. [http://www.unesco.org/water/ water_events/Detailed/2077.shtml]. Disponibilidade: 25/03/2011.

UNESCO (2011a). Second International UNESCO/UCI 2011 Conference on Groundwater Resources Management: Adaptation Measures to Water Scarcity - Science and Policy Responses. Water Events World Wide: Irvine. Publicado em Unesco. Org. [http://www.unesco.org/water/ water_events/Detailed/2168.shtml]. Disponibilidade: 25/03/2011.

UNESCO (2011b). Fourth United Nations Conference on Least Developed Countries. Water Events World Wide: Istambul. Publicado em Unesco. Org [http://www.unesco.org/new/en/ natural-sciences/environment/water/wwap/]. Disponibilidade: 25/03/2011. 
UNESCO (2011c). Second International UNESCO/UCI 2011 Conference on Groundwater Resources Management: Adaptation Measures to Water Scarcity - Science and Policy Responses. Water Events World Wide: California. Publicado em Unesco. Org [http://maintenance.unesco. org/404/?host=www.unesco.org\&uri=/new/en/natural-sciences/environment/water/wwap/ index.shtml\#gas_abstracts]. Disponibilidade: 25/03/2011.

UNESCO/ISARM Américas (2010). Acuiferos Transfronterizos de las Américas. Aspectos socioeconómicos, ambientales y climáticos de los Sistemas Acuíferos Transfronterizos de las Américas. Vol. 3. Montevideo/Washington DC.

YELPO, L.; SERRENTINO; C. M. (2000). Informe Sectorial Uruguay: Uruguay y la gestión de sus recursos hídricos, publicado em CEPAL.org [http://www.cepal.org/samtac/noticias/ documentosdetrabajo/1/23451/InUr00100.pdf]. Disponibilidade: 07/03/2013.

Recebido em 15 de setembro de 2014 Aprovado em 4 de dezembro de 2014

\section{Resumo}

Este artigo analisa processos de inovação institucional, com foco para a governança das bacias transfronteiriças dos rios Apa, Acre, Lagoa Mirim e Quaraí, todos situados na América do Sul. Busca-se identificar a internalização de diretrizes internacionais para a gestão de águas e discutir inovações quanto a estruturas de governança desse recurso compartilhado.

Palavras-chave: gestão de recursos hídricos compartilhados; governança de bens comuns; instituições.

\section{Abstract}

This article analyses processes of institutional innovation with focus on governance of transboundary basins of Apa, Acre, Lagoa Mirim and Quaraí rivers, all located in South America. It seeks to identify the internalization of international guidelines for management of waters and discuss innovations in the governance structures of shared water.

Keywords: management of shared water resources; governance of global commons; institutions. 